\title{
El mundo funerario augusteo en la Hispania meridional. Una aproximación arqueológica
}

\author{
José BELTRÁN ForTeS \\ Universidad de Sevilla \\ jbeltran@us.es
}

\section{RESUMEN}

Se estudia el proceso de monumentalización funeraria en la Hispania meridional centrado en la época de Augusto a través de documentación arqueológica y epigráfica a fines del siglo I d.C. Los cambios sociales y económicos que tienen lugar en la Hispania Ulterior en el período tardorrepublicano eclosionan en época de César y Augusto (con los nuevos municipia y coloniae). Ello produce un importante cambio en las necrópolis urbanas, con la adopción de tipos de monumenta propios de Roma y la Península Itálica. La arqueología del mundo funerario de ese período en las ciudades del sur de Hispania documenta ese proceso de cambios culturales e ideológicos a través de las tumbas.

Palabras clave: Arqueología funeraria romana. Bética augustea. Monumenta.

\section{The Augustean Funerary World in Southern Hispania. An Archaeological Study}

\begin{abstract}
In this paper it is studied the process of the use of monumenta in southern Hispania through the archaeological and epigraphic documents at the end of the first century AD. The social and economic changes that occur in Hispania Ulterior in the late Republican time emerge in the age of Caesar and Augustus (with new municipia and coloniae). It produces an important change in the urban necropolis with the adoption of the monumenta caracteristic of Rome and the Italian Peninsula. The funerary archaeology of this time in the cities of southern Hispania proves this process of cultural and ideological changes and adaptations through the graves.
\end{abstract}

Key Words: Roman Funerary Archaeology. Augustean Baetica. monumenta. 
Si la Hispania Ulterior Baetica "nace" con Augusto, podemos afirmar, al menos de manera general, en principio, que fue en ese largo período del principado augusteo cuando comienza a hacerse efectiva en muchas de las comunidades de la nueva provincia la transformación de los espacios sepulcrales, disponiéndose necrópolis urbanas a la manera romana, ${ }^{1}$ tal como se habían ido conformando en la Península Itálica a lo largo del siglo I a.C. Como es sabido, en Italia se conforman verdaderas viae sepulcrales ${ }^{2}$ donde surge una típica arquitectura funeraria, a base de monumenta, de tipología diversa, sobre todo, tumbas con frisos dóricos y coronados por pulvinos -en forma de altar-o por edículas abiertas donde se exponían los retratos funerarios o por tipos turriformes cerrados. ${ }^{3}$ En todos los casos de forma usual se asocian al denominado "friso dórico" - con metopas decoradas con diversos motivos- como principal elemento ornamental del cuerpo inferior, y en ocasiones se vinculan asimismo a pilastras con función pseudo-arquitectónica. ${ }^{4}$ Con un carácter autorrepresentativo y exteriorizador/propagandístico de las oligarquías ciudadanas se desarrolla asimismo la escultura, tanto mediante relieves de simbología diversa o estatuaria de bulto redondo, destacando los retratos funerarios, así como la epigrafía sepulcral. Arquitectura, escultura e inscripciones conforman un nuevo lenguaje en el paisaje suburbano, con esa monumentalización del ámbito funerario, que dará lugar a verdaderas necrópolis, ${ }^{5}$ ciudades de muertos con grandes monumenta conmemorativos, como ocurre tanto en Roma como en la Península Itálica (Fig. 1). Aunque se mantienen ciertas características, sobre todo, el friso dórico, en los territorios de las provincias occidentales se documentan desarrollos concretos bastante diferenciados, que pueden conformar áreas con características peculiares a nivel local o regional, como nos pueden ilustrar, por ejemplo, conjuntos como los itálicos de Sarsina ${ }^{6}$ o Aquileia, ${ }^{7}$ o ejemplos singulares como el complejo mausoleo de los Julios en Saint-Rémy, ${ }^{8}$ en la Galia Narbonense (nadie hubiera supuesto el coronamiento de la tholos si no se hubiera conservado), o -ya en Germania- el mausoleo de Lucio Poblicio, ${ }^{9}$ en Colonia.

Como se indicaba al inicio, ese mismo planteamiento comienza a constatarse de manera más generalizada en la parte meridional de Hispania precisamente desde época augustea, frente a unos precedentes más raros y excepcionales que se pueden constatar en algunos casos en momentos tardorrepublicanos preaugusteos, desde los inicios del siglo II a.C. ${ }^{10}$ No nos detendremos mucho en ellos, pues son anteriores al momento cronológico sobre el que se centra este congreso, pero sí debemos destacar -por el contraste que supone con lo posterior-esa escasa documentación arqueológi-

1 Por ejemplo, Hesberg 1993; Beltrán 2002; VAqUerizo 2010.

2 HeSBERG - ZANKer 1987.

3 Hesberg 1992.

4 Es clásico Torelli 1965. Para los ejemplares hispanos, Gutiérrez 1990.

5 Cfr., por ejemplo, VAquerizo - Garriguet - León 2006 y Vaquerizo 2010a, con especial referencia al Occidente romano.

6 Aurigemma 1963.

7 Santa Maria Scrinari 1972.

8 Rolland 1969. En general, sobre la arquitectura funeraria monumental gala, MoRETTI - TARDY 2006.

9 Precht 1975. Cfr., en general, Scholz 2012.

10 Noguera - Rodríguez 2008; Beltrán 2009. Cfr., Ruiz 2008 (para la Bética) y 2010 (para Corduba). 
ca datable en el período preaugusteo, tanto desde el punto de vista de la arquitectura funeraria, cuanto de la escultura y epigrafía asociadas a aquélla. En efecto, prácticamente el material arqueológico que sustenta ese proceso en momentos tardorrepublicanos preaugusteos en la Hispania meridional lo constituyen las representaciones escultóricas zoomorfas, especialmente de leones, asociados o no a cabezas de carneros y humanas, como protectores de las tumbas y de las almas de los difuntos en el Más Allá. ${ }^{11}$ Tradicionalmente se hablaba de un período tardoibérico en esa escultura zoomorfa, que ocuparía los siglos III, II y I a.C., pero con el grave error conceptual -a mi juicio- ${ }^{12}$ de no tener en cuenta el trascendental cambio de tipo político que significa el que estos territorios meridionales pasen de forma efectiva bajo el control romano, sobre todo, tras la constitución de la provincia Hispania Ulterior en el 197 a.C.

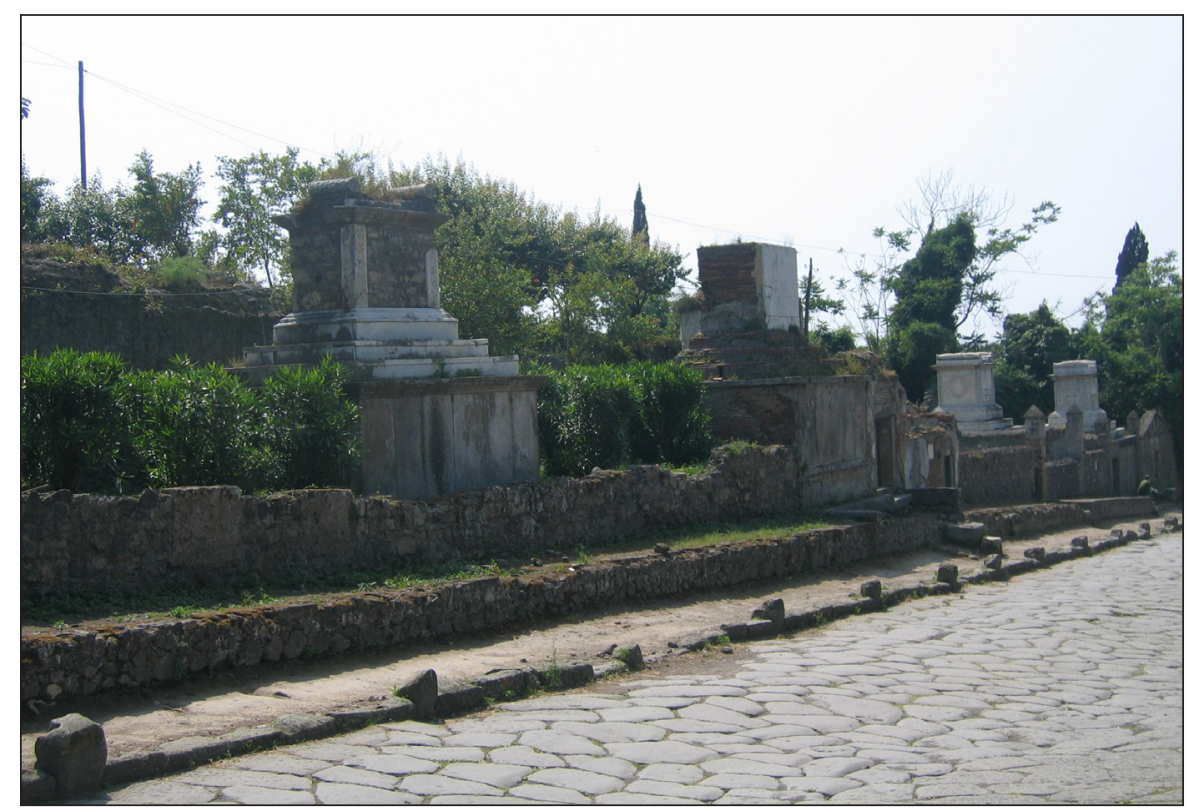

Fig. 1. Pompeya. Vista de la necrópolis de Porta Ercolano. Foto: J. Beltrán.

Por otro lado, hoy sabemos que en la Turdetania no se constata una escultura funeraria zoomorfa de gran formato de época ibérica, por lo que las representaciones leoninas del bajo Guadalquivir son exclusivamente de época republicana y responden a la asimilación de los modelos romano-itálicos. Esa hipotética línea de perduración (o más bien de confluencia) con la producción zoomorfa de momentos ibéricos anteriores al siglo II a.C. sólo se podría mantener entonces para el alto Guadalquivir y la Andalucía oriental; es decir, grosso modo, para los antiguos territorios de oretanos y bastetanos, a pesar de las dificultades que todos conocemos y que se han destaca-

11 López 1999.

12 Hemos tratado esa problemática en BELTRÁN - LOZA 2005. 
do últimamente para definir fronteras étnicas prerromanas con exactitud. ${ }^{13}$ Incluso en estos territorios el principal impulso de este tipo de manifestaciones funerarias llamadas tradicionalmente "tardoibéricas" se centraría sobre todo en los siglos II-I a.C., siguiendo asimismo los modelos romano-itálicos, incluso en esquemas que tradicionalmente se habían vinculado al mundo ibérico, como el del león con la cabeza humana bajo una de las garras. ${ }^{14}$ Desde el punto de vista tipológico se remite especialmente al modelo expresado en la tumba tardorrepublicana de la familia Stronnia, localizada en la necrópolis de Porta Nocera, en Pompeya (Fig. 2), donde dos leones, de tipo naturalístico y con una de las zarpas sobre una cabeza de carnero, coronan los flancos superiores de una tumba "a dado"; es decir, de una cámara sepulcral exenta, elaborada en opus quadratum y con forma cuadrangular o de dado.

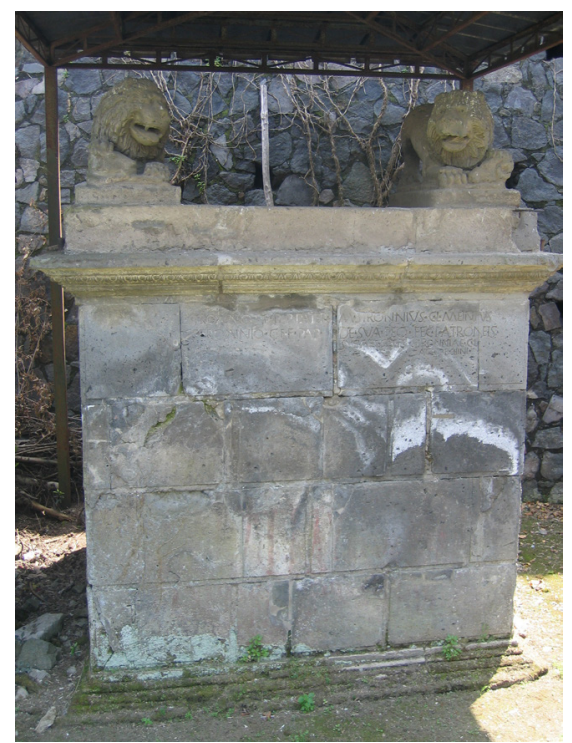

Fig. 2. Pompeya. Monumentum familiar de los Stronnii, en la necrópolis de Porta Nocera. Foto: J. Beltrán.

El problema real es que estos leones surhispanos generalmente los conocemos descontextualizados (en colecciones privadas o en museos publicos). No se ha excavado ninguna de estas tumbas con leones en el sur peninsular hispano, y no se conoce, por tanto, en primer lugar, la tipología exacta de estos monumentos, con lo que no todos los leones podrían coronar tumbas "a dado" en la Hispania meridional. Incluso hay otras soluciones constatadas en el mundo romano, como testimonia por ejemplo un mausoleo de Ostia, de la necrópolis de Porta Marina, con los leones flanqueando el segundo cuerpo arquitectónico en una gran tumba de varios pisos. ${ }^{15}$ En segundo

13 Asimismo hemos tratado el tema en Beltrán 2014b.

14 Aranegui 2004; Beltrán 2006.

15 Hesberg 1992, 137, fig. 81. 
lugar, el desconocimiento de esos contextos arqueológicos hispanos impide establecer una cronología más exacta. Se ha recurrido a criterios estilísticos para datar esas esculturas: los menos naturalísticos (que se considerarían de tradición ibérica) serían más antiguos y los más naturalísticos (entroncados con la tradición romana) serían más modernos; ${ }^{16}$ y aunque pueda ser asumible de manera general, no resuelve los problemas. Así, el problema de la frontera entre la consideración de ibérico y romano republicano para los especímenes menos realistas. Un ejemplo evidente es un león funerario de Conobaria (Las Cabezas de San Juan, Sevilla), que será municipio flavio: presenta un estilo poco natural, pero debe ser cuando menos del siglo II a.C., ya que -como se ha dicho- los turdetanos no tienen escultura zoomorfa de gran formato. ${ }^{17}$

Incluso en el alto Guadalquivir, de la romana Obulco, en Porcuna (Jaén), que se considera municipium augusteo, procede el -denominado- "oso de Porcuna" (Fig. 3), que se ha datado o en el siglo II a.C. o en el siglo I a.C., porque frente al estilo -podríamos decir- "arcaico" de la representación del animal (seguramente un oso y no una leona como se ha dicho también) se une la presencia excepcional de una herma con retrato, un tipo estatuario plenamente romano. Es pieza única, fruto de un eclecticismo local, cuya génesis podemos intuir sólo como fruto de una elección particular y no de la copia de un esquema modelo. Ya hemos destacado en alguna ocasión que precisamente en época augustea se amplió la antigua Obulco con un sector urbano ex novo construido a la romana, con un viario de calles paralelas y una tipología de domus que adapta formas romano-itálicas, pero no en torno a atrios, sino en torno a patios columnados; es el actual sector del barrio de San Benito de Porcuna, excavado hace algunos años por Oswaldo Arteaga, quien estableció que este sector urbano aparece abandonado ya en momentos iniciales de la época flavia. ${ }^{18} \mathrm{De}$ esta zona procede un importante conjunto de pilares hermaicos con inscripción, que conforman el conjunto más importante de la Bética por ahora, y que servían-como es bien conocido- como soportes de retratos de los domini de las casas. ${ }^{19}$ Quizá uno de estos propietarios quiso tener en su tumba también no una genérica referencia a la protección del león sobre el alma del difunto (simbolizada en la cabeza humana colocada bajo una de las zarpas, tan habitual en otras representaciones del alto Guadalquivir) sino que quiso un ejemplo más explícito y original, con su propio retrato casi fisiognómico representado en forma hermaica, tal como era habitual en las domus de la misma Obulco de manera coetánea. Dado que esas hermae-retrato domésticas de Obulco se datarían entre época de Augusto y Nerón, nos parece lógico frente a otros razonamientos estilísticos que el oso de Porcuna hay que datarlo al menos en esa misma cronología augustea o julio-claudia. ${ }^{20}$

Otro ejemplar leonino de Lebrija (Sevilla), la romana Nabrissa, también sería de esa misma cronología, ya que aparte de su representación muy naturalística, dispuso

16 Cfr., por ejemplo, la obra clásica de CHAPA 1985.

17 Beltrán 2007, 130-135, y 2008, 505-507.

18 ARTEAGA ET ALII 1992.

19 Rodríguez-Oliva 1982.

20 Beltrán - Loza 2005. 
una inscripción en el frente de la base del grupo escultórico, aunque ahora sólo se identifican algunas letras latinas en capital cuadrada (Fig. 4). ${ }^{21}$

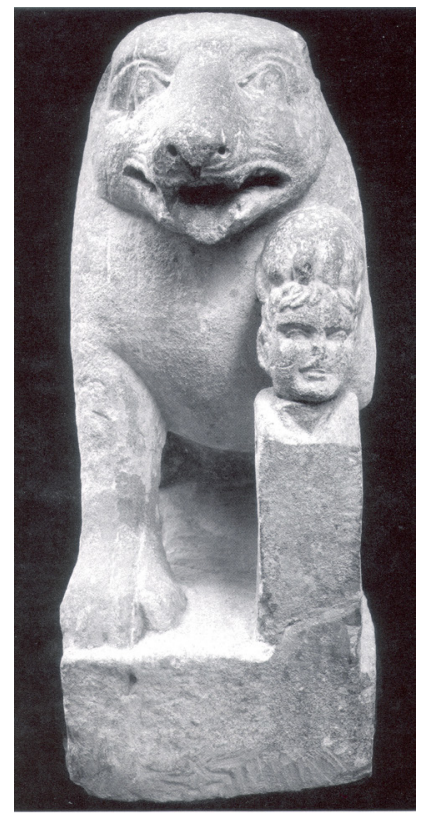

Fig. 3. "Oso de Porcuna". Museo Arqueológico Nacional. Foto: DAI Madrid R76-93-16.

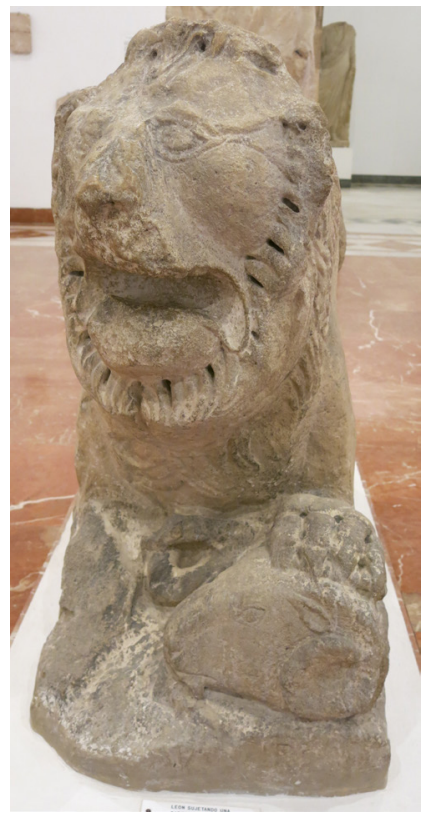

Fig. 4. León de Nabrissa (Lebrija, Sevilla). Museo Arqueológico Provincial de Sevilla. Foto: J. Beltrán.

En ese panorama el caso de Osuna, la antigua Urso, sigue siendo efectivamente excepcional, ya que incorpora junto a las figuras zoomorfas escenas con representaciones humanas. No obstante, en este caso, el conjunto de relieves funerarios, que formarían parte del exterior de monumenta-posiblemente turriformes en algún caso y con basamentos escalonados- y que fueron amortizados por la construcción de la muralla pompeyana ante el avance de César en el 45 a.C., debe ser datado por tanto con anterioridad a la constitución de la colonia Iulia Genetiva y a la época de Augusto. Ya he mantenido en un trabajo anterior que me parece todavía más acertada esa datación tradicional de la muralla, frente a otras hipótesis de considerarla de fecha republicana anterior o incluso protohistórica. ${ }^{22}$ Desde el clásico estudio de Antonio García y Bellido en la década de 1940, con un enfoque luego mantenido y ampliado por otros autores, como Pilar León o Pedro Rodríguez Oliva en fechas más recientes, se considera que de manera excepcional existe en Urso una secuencia entre un conjunto de relieves tardoibéricos (s. III a.C.) y otros varios de época romano republicana, pero esa secuencia no puede establecerse de manera clara, dada la falta de

21 LóPez 1999, 74-75, n²1. GARCía y Bellido (1949) leyó la inscripción como PCPPI.

22 Beltrán 2008a. 
identificación de la estratigrafía y de los contextos arqueológicos en los trabajos de 1903 llevados a cabo por los franceses Pierre Paris y Arthur Engel. ${ }^{23}$ Incluso la serie considerada tardoibérica es datada ahora por Fernando Quesada -por la tipología de las armas representadas- en el siglo II a.C., por lo que todo el proceso monumentalizador arrancaría de momentos republicanos, aunque sin considerar el carácter de la iconografía de las representaciones o la etnia de los difuntos allí sepultados. ${ }^{24}$ Es cierto que frente a esos temas e iconografía de tradición más ibérica (procesiones de guerreros y oferentes femeninas), los posteriores conjuntos que representarían tanto batallas, como venationes anfiteatrales, se adecúan mejor ya a temas e iconografía romanos, datándose entre los últimos decenios del siglo II a.C. y primera mitad del siglo I a.C. ${ }^{25}$ Por el contrario, falta en la colonia Genetiva Iulia -fundación cesariana que se hizo efectiva tras su muerte- ${ }^{26}$ testimonios de las tumbas de época augustea, pues la asimismo conocida como "necrópolis de las Cuevas", situada en el eje viario extraurbano al este de la colonia, es de época imperial avanzada. ${ }^{27}$

Junto a la ausencia de documentación, podemos asimismo enfrentarnos en otros casos a elementos arqueológicos descontextualizados que por el simple análisis tipológico o estilístico no podemos establecer de manera exacta si se construyeron o elaboraron en época de Augusto o en los decenios siguientes de la dinastía julio-claudia. Sí hay más margen de aproximación cuando junto al resto arquitectónico aparece la inscripción del monumentum o los elementos escultóricos, sobre todo los retratos funerarios, que sí responden a tipos y formas mejor conocidos y que en ocasiones podrían datarse más ajustadamente por esos criterios de forma y estilo. En efecto, es difícil discernir si un monumentum romano del sur hispano es de época augustea o julio-claudia sólo por la tipología arquitectónica, sin contar con el contexto arqueológico, inscripciones o esculturas. Así, todo ello determina una serie de problemas que hacen difícil establecer exactamente, con fases precisas en cada caso, ese proceso de cambio de las áreas sepulcrales suburbanas seguido en el sur de Hispania en momentos augusteos. Cuando falta la documentación no sabemos si fue realmente porque no se produjo ese proceso de monumentalización funeraria en época augustea, o si es consecuencia de la amortización de los restos arqueológicos en momentos posteriores, o de la simple ausencia de investigación y del azar en los descubrimientos.

En fechas recientes sí podemos destacar intervenciones más frecuentes en áreas sepulcrales de ciudades romanas como fruto del desarrollo de la arqueología urbana en ciudades actuales, como, por ejemplo, ha ocurrido en Gades o Corduba. ${ }^{28}$ Por el contrario son pocas las necrópolis urbanas excavadas en extensión y las de mayor interés corresponden a excavaciones, como las de Carmo o Baelo Claudia, excavadas por Jorge Bonsor (la segunda junto a Pierre Paris) entre fines del siglo XIX y los primeros decenios del XX, si bien es cierto que estudios recientes están actualizando los

23 Beltrán - Salas 2002.

24 Quesada 2008. Sigue esa datación CHAPa 2012.

25 Cfr., Noguera - Rodríguez 2008.

26 Caballos 2006.

27 PACHÓN - RUIZ 2006.

28 Una síntesis en VAquerizo 2010. 
datos e interpretación. ${ }^{29}$ Más recientes son las excavaciones de la necrópolis oriental de Munigua, perfectamente planteadas desde el Instituto Arqueológico Alemán de Madrid, pero en ésta no se advierte una monumentalización sepulcral, con la excepción de un mausoleo, con sarcófagos en su interior, pero no de época augustea, sino ya del siglo II d.C. ${ }^{30}$

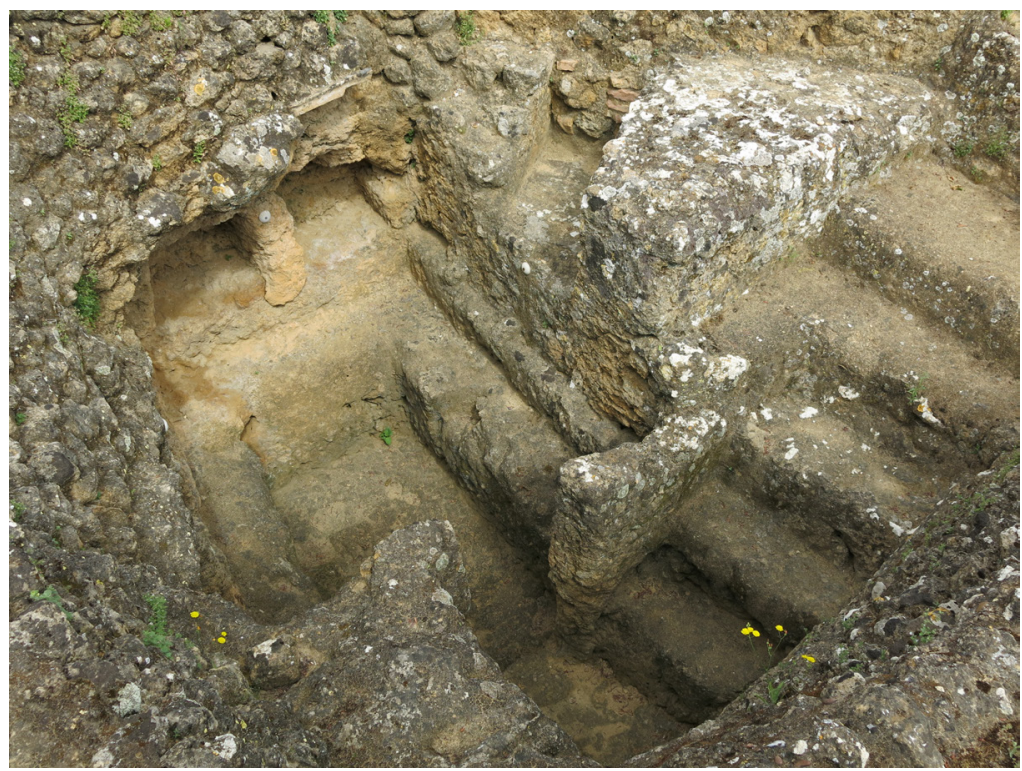

Fig. 5. Cámara hipogea de una tumba de la necrópolis occidental de Carmo (Carmona, Sevi1la). Conjunto Arqueológico de Carmona. Foto: J. Beltrán.

En las ciudades costeras como Gades o Baelo Claudia se advierte una monumentalización particular, con tipos sepulcrales que parecen vincularse a perduraciones púnicas y modelos norteafricanos, de raigambre helenística, como demostrarían los monumentos turriformes con coronamientos piramidales o las tumbas de cámaras hipogeicas, si bien otros autores consideran que estos rasgos también pueden asociarse a esquemas testimoniados en la Península Itálica. ${ }^{31}$ Singular -sobre todo, por el ajuar- es un enterramiento infantil de Gades, asociado a una estructura de sillares, que ha sido interpretada bien como el basamento de un mausoleo turriforme o bien como una cista, en la que aparece un excepcional conjunto de elementos tallados en cristal de roca, junto a dos vasos egipcios de alabastro, reutilizados en el ajuar, y elementos de ámbar, en un enterramiento que se ha datado en época julio-claudia, pero sin poder precisar si en época de Augusto o -posiblemente- algo posterior, ejemplo

29 Para la de Carmona puede verse, ahora, RodríGUEZ ET ALII 2012; para la de Baelo, JimÉNEZ 2008. Una revisión histotiográfica de la segunda y la figura de Jorge Bonsor en AA.VV. 2009.

30 Cfr., Beltrán 2012, 75-77.

31 VAqUeRIZO 2006 y 2008. 
de la imponente riqueza de las elites gaditanas en los comienzos del Imperio. ${ }^{32} \mathrm{En}$ otros casos sí es evidente la relación con talleres de la propia Roma, como ocurre con una urna asimismo gaditana, decorada con relieves, hoy en paradero desconocido, pero dibujada en el siglo XVIII por el conde de Caylus, referida por Antonio Ponz y llevada a Francia por Alejandro de Laborde..$^{33}$ Sobre esas dos diversas interpretaciones que podríamos denominar "filopúnica" o "filorromana" 34 el caso de Carmo -bien conocido- es paradigmático (Fig. 5), desde las posturas tradicionales, planteadas por G. Bonsor y desarrolladas científicamente por M. Bendala, de considerar la necrópolis oriental como una verdadera necrópolis "neopúnica", ${ }^{35}$ hasta otras interpretaciones (G. Alföldy, A. Caballos, I. Rodríguez Temiño y otros), donde se destacan que los aspectos formales (entre ellos ciertas tipologías de las tumbas) la acercarían mejor a modelos romanos. ${ }^{36} \mathrm{Se}$ le da una básica datación julio-claudia, pero sería difícil establecer exactamente cuáles de esas tumbas fueron construidas exactamente en época augustea y cuáles posteriormente.

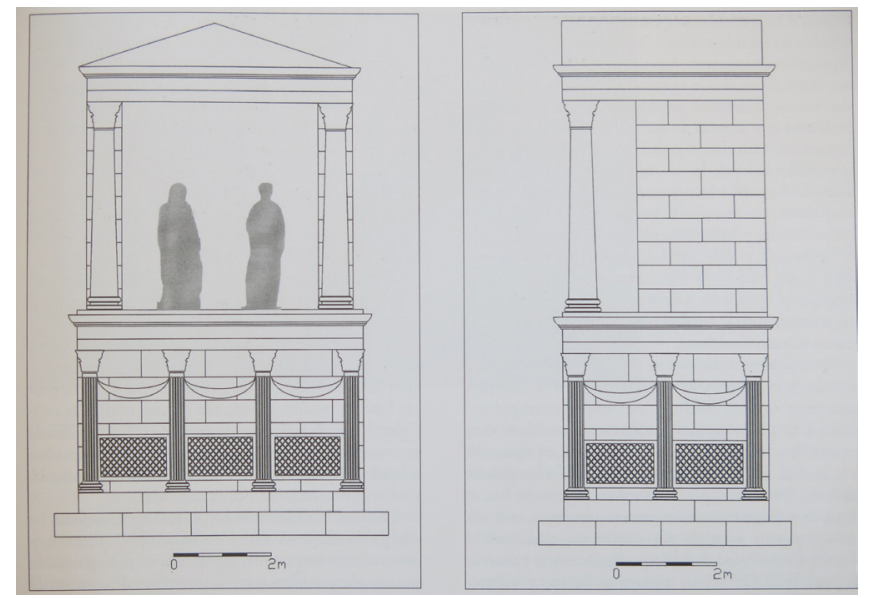

Fig. 6. Restitución ideal del monumentum de c/ Muñices, Colonia Patricia Corduba (Córdoba), según Ruiz, 2010.

En este punto, tendríamos que detenernos, especialmente, en el caso de las colonias fundadas en la Hispania meridional en época de Augusto, para ver en ellas cómo se produce el cambio en esos primeros momentos, teniendo en cuenta la significativa nueva presencia de los colonos en esos momentos, aunque con la problemática bien conocida de la relación con las colonias de época de César, en muchas de las cuáles hubo nuevas deductiones augusteas, según parece indicar en algún caso la adscripción en una misma comunidad de ciudadanos tanto a la tribus Sergia como a la Galeria. ${ }^{37}$

32 López de LA ORden 2009; LuZÓN 2010, 286-295.

33 RodríGUEZ 1991-1992; RodríGUEZ - BELTRÁN 1997-1998.

34 Puede verse, a nivel general, MORA - Cruz 2012.

35 Bendala 1976.

36 Alföldy 2001; Caballos 2001; Rodríguez et alit 2012. Cfr., Beltrán 2012.

37 Una actualización en GonzÁLEZ - SAQuete 2011. 
El primer ejemplo lo debe constituir el caso de Corduba, la augustea colonia Patricia, capital de la provincia, donde además se ha desarrollado en los últimos años un importante proyecto de investigación específico sobre el mundo funerario de época romana. ${ }^{38}$ Aquí se destaca que quizás ciertas formas de cámaras hipogeicas, pero con recinto y monumento supraestante, podrían deberse a influencias o perduraciones púnicas, si bien no se datan en época augustea, sino posteriormente. ${ }^{39}$ Por el contrario para el cambio de Era se han documentado, sobre todo, recintos de muros bajos (llamados asimismo acotados), con inscripciones que delimitan la extensión y que continúan al menos durante época julioclaudia. ${ }^{40}$ En el interior de uno de ellos, en c/ Muñices, al pie de la via Augusta vetus antes de su entrada en la ciudad por el este, se construyó un monumentum de dos pisos coronado con edícula (Fig. 6), del que se conserva parte de una estatua sepulcral femenina, en un tipo iconográfico en el que el manto cubre todo el cuerpo y que María Luisa Loza ha puesto en relación con el ricinium, un vestido de luto. ${ }^{41}$ Interesante es que la decoración relivaria del monumentum no se hace en los sillares, sino como placas de caliza, estucadas y luego pintadas, que se adosan a la obra arquitectónica, con un esquema de pseudopilastras de cuyos capiteles cuelgan guirnaldas y con celosías bajas. ${ }^{42}$ Ese mismo esquema denota un bloque descontextualizado donde se aprecia la zona alta del fuste de la pilastra y parte de la guirnalda de frutos y flores, en un estilo que se asemeja al del alto Guadalquivir (Fig. 7), como se verá luego. ${ }^{43} \mathrm{~A}$ ese mismo ámbito remiten otros bloques asimismo descontextualizados y decorados con relieves de guirnaldas de las que cuelgan erotes alados que sostienen atributos, como la cista mystica de carácter báquico. ${ }^{44}$ En este caso coincide el tema, aunque no el estilo. Ya a época de Tiberio debe llevarse la construcción de los dos impresionantes mausoleos cordobeses en forma de tumulus, en una tipología clásica que entronca con el propio mausoleo de Augusto y su tradición anterior. ${ }^{45}$

Muchos menos datos contamos para otras colonias césaro-augusteas de ese momento, como ocurre, por ejemplo, con Iulia Romula Hispalis, Augusta Firma Astigi, Claritas Iulia Ucubi, la ya citada Genetiva Iulia Urso, Iulia Gemella Acci, o -ya en el conventus Gaditanus- Hasta Regia o Asido Caesarina ${ }^{46}$ Por el contrario, la colonia augustea Virtus Iulia, situada en el yacimiento de Torreparedones, ofrece un testimonio singular: una verdadera via sepulcralis, que se ha localizado por prospección geofísica y donde se ha vuelto a recolocar el emplazamiento de la famosa tumba de los Pompeyos, aparecida en 1833 y de la que se desconocía hasta ahora su ubicación

\footnotetext{
38 RuIZ 2010; VAQUERIZO 2010, 105-142.

39 VAQUERIZO 2006.

40 VAQUERIZO 2002.

41 LozA 2010.

42 RuIz 2007, figs. 7 y 8.

43 Ruiz - OrTIZ 2009; VAQUERIzo 2010, fig. 80.

44 Vaquerizo 2002a, 189-193, figs. 23-24.

45 Murillo ET ALII 2002.

46 Cfr., González - SAQuete 2011.
} 
exacta. ${ }^{47}$ Del estudio que hemos hecho de los dibujos y descripciones del siglo XIX y, sobre todo, del análisis de las inscripciones de las urnas podemos pensar que la tumba familiar estuvo en uso en época augustea, incluso que fuera construida entonces o-en todo caso- en un momento muy poco anterior.

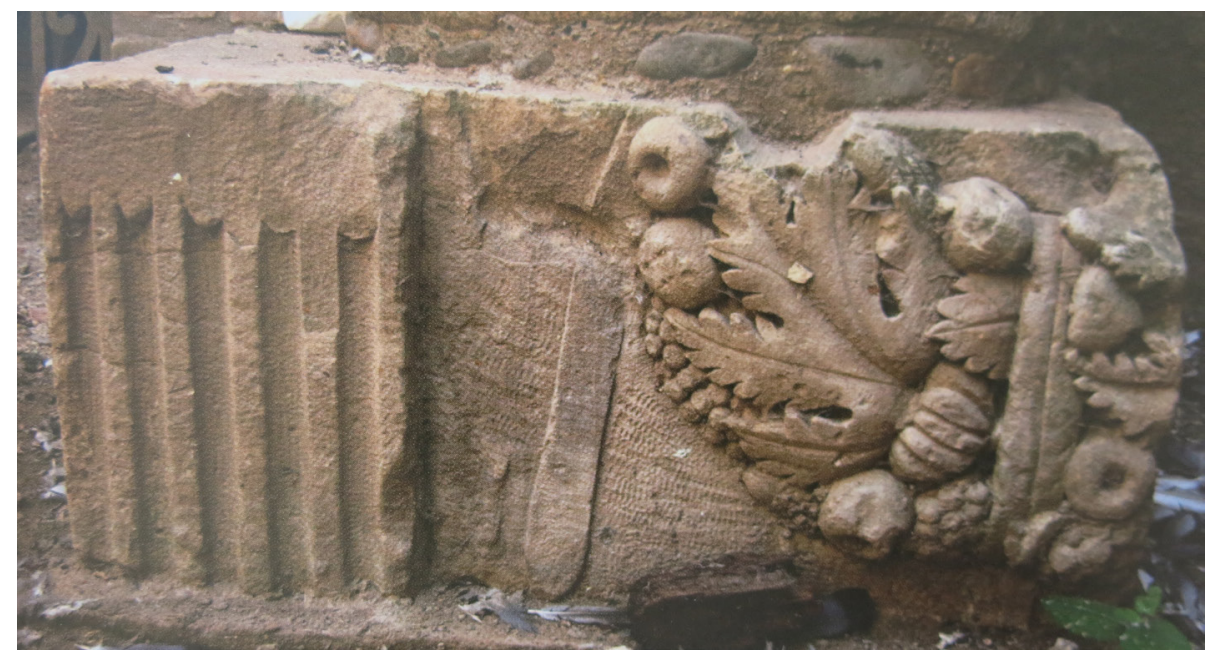

Fig. 7. Bloque con relieves de carácter funerario, de un monumentum de Colonia Patricia Corduba (Córdoba). Foto: Vaquerizo, 2010.

Hoy conocemos cómo estaban colocadas las urnas en la tumba -por un dibujo de Fernández Guerra de 1834, que había permanecido inédito- y mediante el análisis de esa interpretación hemos planteado la hipótesis ${ }^{48}$ de que fuera Quintus Pompeius $Q$ (uinti) f(ilius) Velaunis - sin la referencia aún a la tribus Galeria propia de la colonia- junto a su probable mujer Iunia L(ucii) f(ilia) Insghana los contructores del mausoleo, que flanquea la de Ildrons Velaunis (filius) (Fig. 8). Según esa hipótesis hijos de éstos serían Quintus Pompeius Q(uinti) f(ilius) Sabinus -el primogénito y asimismo sin adscripción a tribus-, la hermana Pompeia Q(uinti) f(ilia) Nanna, y Marcus Pompeius Q(uinti) f(ilius) Gal(eria tribu) Icstnis, que a pesar de que mantiene asimismo un cognomen indígena indica que fue IIvir primus in familia Pompeia y explica su inclusión en la tribus de la colonia augustea. La urna de Ildrons Velaunis (filius) ocupa el centro de la pared frontera a la entrada de la cámara sepulcral, en un lugar privilegiado y debió ser un antecesor distinguido de la familia, una vez que Quintus Pompeius Velaunis recibiera la ciudadanía y el acceso a la gens Pompeia. Precisamente el nombre indígena del padre de Ildrons, Velaunis -que no está enterrado en la tumba-, es el cognomen que presenta Quintus Pompeius Velaunis, ese posible constructor de la tumba y pater familias.

47 Sobre la tumba, BELTRÁN ET ALII 2010. En general, sobre el yacimiento, MÁRQUEZ 2014, con bibliografía anterior.

48 Beltrán 2014a. 


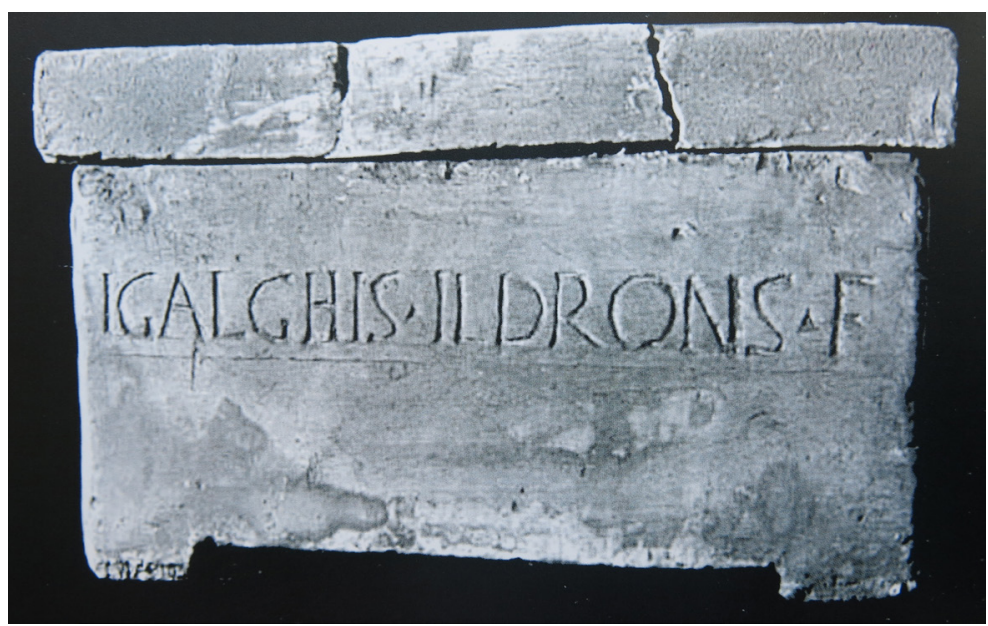

Fig. 8. Copia en yeso de la urna cineraria de Ildrons Velaunis (filius), del "mausoleo de los Pompeyos” (Torreparedones, Baena, Córdoba). Museo Arqueológico Nacional, Madrid.

Problemática distinta corresponde -ya en la campiña de Jaén- a la tumba familiar de los Stlaccii, de la colonia de Salaria (cortijo Doña Alconza, Úbeda), ya que nos encontramos una tumba construida seguramente en época de Augusto, tras la constitución de la colonia, puesto que Marcus Stlaccius sería posiblemente un colono itálico, pues a la Italia central apunta como procedencia el gentilicio. A partir de una serie de piezas aisladas, recuperadas en la década de 1960 y hoy en el Museo de Úbeda, reconstruimos hace ya algunos años una tumba de edícula, ${ }^{49}$ que servía para exponer las estatuas funerarias, de las que se recuperó una femenina, que lleva bajo el velo el peinado de nodus -típico de época augustea- y se representa según el tipo de la Pudicitia, especialmente apropiado para el ámbito funerario en el mundo romano. Lo más interesante es que pudimos restituir la existencia de un friso epigráfico, que se colocaría en el cuerpo inferior, flanqueando el campo epigráfico -al menos en dos columnas- son sendas máscaras báquicas y un motivo de meandros entrelazados en los laterales, que sustituye al típico friso dórico. Frente a la consideración tradicional de identificar dos miembros masculinos de la gens Stlaccia, Marcus -abreviado- y Sextus, desarrollado en la segunda línea del epígrafe fragmentado conservado (Fig. 9), y que inusualmente continuaría el nomen en la línea tercera, creemos que en la línea segunda se desarrolla la tribus Sergia, asimismo documentada en Salaria ${ }^{50}$ En ese caso el personaje de línea $3^{\mathrm{a}}$ es la mujer, Stlaccia, que es la representada en el retrato. Anecdóticamente sería el retrato particular nominado más antiguo de la Bética. La similitud del gentilicio con su marido apunta a una procedencia indígena y que recibiría la ciudadanía al casarse con el colono salariense. ${ }^{51}$

49 Beltrán - Baena 1996.

50 CILA Jaén, $\mathrm{n}^{\circ} 542$.

51 Con el conjunto de piezas de la década de 1960 había aparecido asimismo un león con una de sus garras sobre una cabeza humana y que presentaba una entalladura en su lado izquierdo, lo que indicaba que no era 


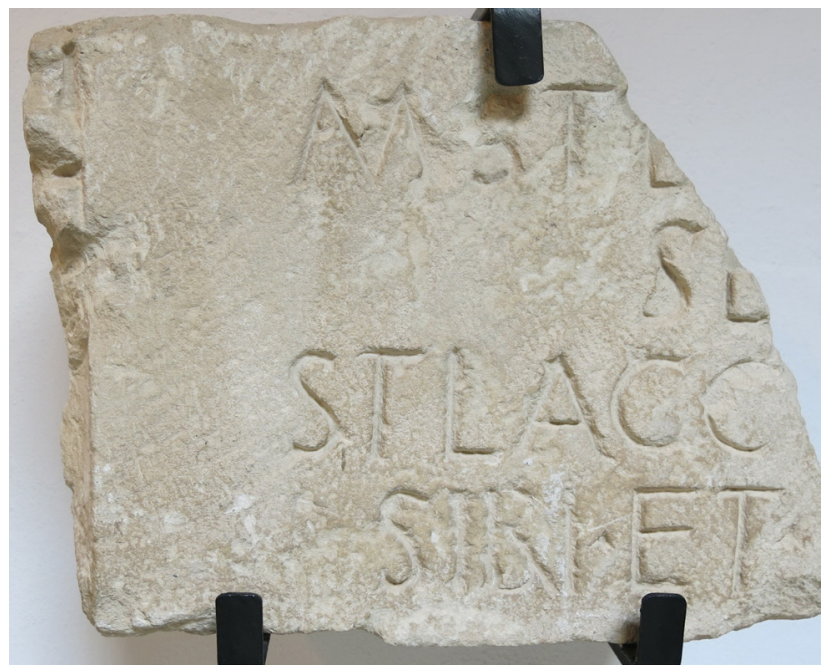

Fig. 9. Bloque con inscripción del monumentum de los Stlaccii, de Salaria (Úbeda, Jaén). Museo Arqueológico Municipal de Úbeda. Foto: J. Beltrán.

Ya hemos dado a conocer en otros trabajos cómo en un amplio sector de la campiña giennense repertorios funerarios similares se desarrollan en ciudades como Castulo, Tugia, Ossigi, etc. (en la Tarraconense) e Iliturgi (en la Bética, aunque en el límite con la anterior), al menos desde época de Augusto y época julio-claudia especialmente. ${ }^{52}$ En su gran mayoría corresponden a municipios de época augustea, con lo que las nuevas elites municipalizadas de esas comunidades asimismo adaptaron los modelos que los nuevos colonos conocían ya en la Península Itálica. En ningún caso se emplea el friso dórico, sino otras variantes, que denominamos como de metopas alternas (muchas de ellas con máscaras báquicas o teatrales, con esvásticas o meandros, etc.), o de frisos de roleos o zarcillos acantiformes. Asimismo guirnaldas que cuelgan de pilastras y de las que cuelgan atributos y objetos relacionados sobre todo con el culto báquico y, quizás, con el metroáco, pero que en otras ocasiones se pueblan de erotes que los sostienen. Ello remite, por ejemplo, a los esquemas que ya vimos en Corduba, por lo que se ha planteado que la moda y los artesanos vienen desde la capital de la provincia a través de la ciudad de Castulo, la gran ciudad minera, ${ }^{53}$

una escultura para ser colocada encima de la tumba, como la pompeyana de los Stronnii, según decíamos antes, sino para ser adosada a una estructura arquitectónica. Hemos podido recientemente identificar, junto a un recipiente pétreo, que de manera habitual corona este tipo de edificios sepulcrales, otro león de Salaria, que es muy posiblemente del mismo monumentum, dada la similitud formal y estilística con el león anterior, aunque éste está más completo y fue ejecutado en un solo bloque. También tiene la misma entalladura en el lado contrario, su parte derecha, para colocarse en el otro lado del monumentum, por lo que proponemos una nueva solución, con dos leones a los lados. El paralelo con otros edificios como el ya citado mausoleo de Ostia de Porta Marina, avala esa solución, que por las referidas entalladuras y las dimensiones apuntan a esta colocación y no en la parte del tejado, como acróteras. Tenemos en estudio la propuesta de restitución.

52 Beltrán - BAena 1996; BAena - Beltrán 2002.

53 Ruiz 2008 y 2010. Cfr., VAquerizo 2010: 298. 
pero no parece demostrable en el estado actual de la investigación, dados los pocos testimonios cordubenses y el enorme volumen localizado en estas necrópolis urbanas del alto Guadalquivir, así como a que también el arranque del fenómeno es coetáneo en ambas áreas en la época de Augusto. Por tanto, más bien pudo corresponder a influencias paralelas y coetáneas que vienen directamente desde la Peninsula Itálica, como fruto de las nuevas presencias humanas foráneas y de los profundos cambios socieconómicos que supuso la época de Augusto en ambos sectores, ${ }^{54}$ que -tampoco debe olvidarse- corresponden a provinciae diferentes, pues el gran núcleo giennense se sitúa en la Tarraconense, al menos tras el desgajamiento del saltus Castulonensis de la Bética en momentos tardoaugusteos.

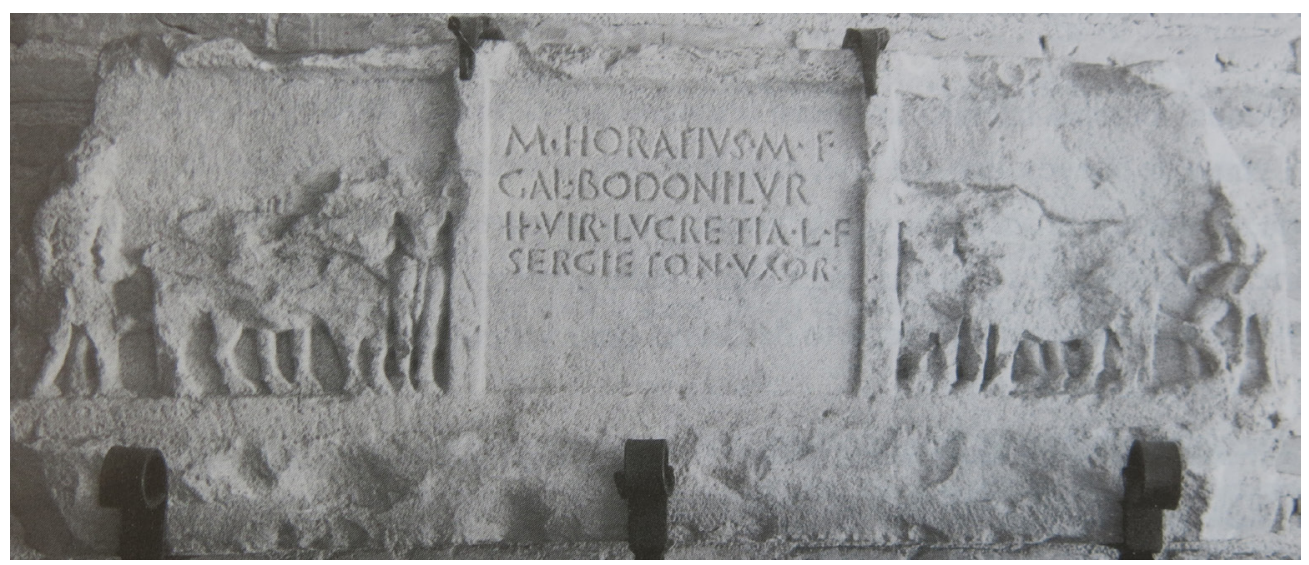

Fig. 10. Friso epigráfico de un monumentum de Urgavo (Arjona, Jaén). Palacio episcopal de Jaén. Foto: J. Beltrán.

Por otro lado, en la otra colonia de esta época en las campiñas giennenses, Iulia Gemella Tucci (Martos), dentro ya de los límites de la Bética, no hay un repertorio similar de arquitectura sepulcral, ni tampoco en otros municipios augusteos como Obulco (Porcuna), del que referimos anteriormente el "oso de Porcuna", o Isturgi (Andújar); sólo sobresale en la parte bética la ciudad de Iliturgi (Mengíbar) con una serie muy completa. ${ }^{55}$ Por tanto, no conocemos por ahora a qué se debe esa expansión concreta y seguramente junto a los intereses de las nuevas gentes llegadas ahora hay que contar con las reminiscencias de las elites que se habían ido conformando en los dos siglos anteriores, en conexión con las anteriores oligarquías ibéricas.

Ello se denota -por último- en el también municipio augusteo de Urgavo (en la actual Arjona), en el territorio bético, al que corresponde el bloque asimismo del friso epigráfico de una tumba familiar, flanqueado por sendas escenas de arado (Fig. 10). ${ }^{56}$ En la inscripción se dice que el difunto, Marcus Horatius M(arci) f(ilius) Gal(eria

54 BELTRÁN - BAENA 1996, 169-181.

55 La escultura se esas ciudades antiguas se recoge toda en BAENA - BELTRÁn 2002.

56 Beltrán - BAena 1996, 93; BAena - Beltrán 2002, 71. 
tribu) Bodonilur, había sido IIvir del municipio, si bien su cognomen indígena, así como el de su mujer Lucretia Sergieton, apuntan a que, aunque ambos eran ciudadanos romanos y pertenecían a la oligarquía urgavonense a los comienzos del siglo I d.C., tenían ascendientes indígenas en el mundo ibérico. En conclusión, el ámbito funerario en el proceso de monumentalización arquitectónica que arranca desde época de Augusto en la Hispania meridional tenía, pues, recursos para recordar el origen local de sus elites, claramente había adaptado esquemas foráneos, del mundo romano-itálico, conformando un nuevo paisaje sepulcral en las ciudades, que -dentro de su diversidad- es uno de los apartados más interesantes que la Arqueología y la Historia Antigua tienen hoy día como objeto de estudio para comprender ese proceso que hemos dado en denominar como romanización y que tiene en el período augusteo un momento determinante.

\section{Bibliografía}

AA.VV. (2009): Jorge Bonsor y la recuperación de Baelo Claudia (1917-1921), Sevilla.

AlföLdy, G. (2001): "La sociedad del municipio de Carmo", [en] CABallos, A. (ed.), Carmona Romana. Actas del II Congreso de Historia de Carmona, Sevilla, 339-362.

Arteaga Matute, O. et aliI (1992): "El abandono de un sector urbano de Obulco en época flavia", [en] Anuario Arqueológico de Andalucía/1990, vol. II, Sevilla, 310-316.

ARANEGUI Gascó, C. (2004): "Leones funerarios de época iberorromana. La serie asociada a cabezas humanas", [en] IV Reunión sobre Escultura Romana en Hispania (Lisboa, 2002), Madrid, 213-227.

Aurigemma, S. (1963): I monumenti funerari di Sarsina (=Bullettino del Centro Studi di Storia dell'Architettura 19), Roma, 1-107.

BAena del AlcÁzar, L. - Beltrán Fortes, J. (2002): Las esculturas romanas de la provincia de Jaén (=CSIR. España 1, 2), Murcia.

BELTRÁN ForTes, J.

(2002): "La arquitectura funeraria en la Hispania meridional durante los siglos II a.C.-I d.C.", [en] D. Vaquerizo (ed.), Espacio y usos funerarios en el Occidente romano, vol. I, Córdoba, 293-328.

(2006): "Esculturas romanas de Arva (Alcolea del Río, Sevilla) conservadas en el Museo Arqueológico de Sevilla", [en] D. Vaquerizo - J. Murillo (eds.), El concepto de lo provincial en el mundo antiguo. Homenaje a Pilar León, vol. II, Córdoba, 669-679.

(2007): "Los tiempos romanos: la ciudad de Conobaria", [en] Arqueología en el Bajo Guadalquivir. Prehistoria y Antigüedad de Las Cabezas de San Juan, Sevilla, 119-181.

(2008): "Esculturas romanas de Conobaria (Las Cabezas de San Juan) y Vrso (Osuna), La adopción del mármol en los programas estatuarios de dos ciudades de la Baetica", [en] J. M. Noguera - E. Conde (eds.), Escultura Romana en Hispania V, Murcia, 501-543. (2008a): "La arqueología cesariana de la provincia Hispania Vlterior", [en] M. P. GarcíaBellido - A. Mostalac - A. Jiménez (eds.), Del Imperium de Pompeyo a la Auctoritas de Augusto. Homenaje a Michael Grant (=Anejos de AEspA XLVII), Madrid, 67-83.

(2009): "Precedentes", [en] P. León (coord.), Arte Romano de la Bética. Escultura, Sevilla, $16-39$. 
(2010): "Estudio arqueológico de «la Tumba de los Pompeyos»", [en] J. Beltrán Fortes et alii, El mausoleo de los Pompeyos de Torreparedones (Baena, Córdoba). Análisis historiográfico y arqueológico, Madrid-Baena, 75-140.

(2012): "Arqueología del mundo funerario de época romana en los territorios de la actual provincia de Sevilla. Una revisión histórica de la investigación”, [en] J. Beltrán - S. Rodríguez de Guzmán (eds.), La Arqueología Romana de la provincia de Sevilla. Actualidad y perspectivas, Sevilla, 61-96.

(2014a): "La necrópolis norte", [en] C. Márquez et alii (eds.), Torreparedones. Investigaciones arqueológicas (2006-2012), Córdoba.

(2014b): "Identidades cívicas en época romana republicana y altoimperial (ss. II a.C. - I d.C.) en la Hispania meridional. Los antiguos territorios de la Turdetania y la Oretania: algunas consideraciones sobre la escultura funeraria como tema de análisis", [en] T. Tortosa (ed.), Diálogo de identidades. Bajo el prisma de las manifestaciones religiosas en el ámbito mediterráneo (siglos III a.C. - I d.C.), (=Anejos de AEspA LXXII), Madrid, 251-273.

Beltrán Fortes, J. - BAENA del Alcázar, L. (1996): Arquitectura funeraria romana de la colonia Salaria. Ensayo de sistematización de los monumenta funerarios altoimperiales del Alto Guadalquivir, Sevilla.

Beltrán Fortes, J. et ali (2010): El mausoleo de los Pompeyos de Torreparedones (Baena, Córdoba). Análisis historiográfico y arqueológico, Madrid-Baena.

Beltrán Fortes, J. - Loza Azuaga, M. L. (2005): "El "oso de Porcuna”: una escultura funeraria excepcional de la Hispania romana", Romula 4, 163-176.

Beltrán Fortes, J. - Salas Álvarez, J. (2002): "Los relieves de Osuna”, [en] F. Chaves (ed.), Urso. A la búsqueda de su pasado, Osuna, 235-272.

Bendala Galán, M. (1976): La necrópolis romana de Carmona, Sevilla.

Caballos Rufino, A.

(2001): "La paulatina integración de Carmo en la romanidad", [en] A. Caballos (ed.), Carmona romana, Sevilla, 13-18.

(2006): El nuevo bronce de Osuna y la política colonizadora romana, Sevilla.

Chapa Brunet, T.

(1985): Escultura ibérica zoomorfa, Madrid.

(2012): "La escultura en piedra de la antigua Osuna: algunas reflexiones sobre los relieves "ibéricos", Cuadernos de los Amigos de los Museos de Osuna 14, 35-41.

García y Bellido, A. (1949): Esculturas Romanas de España y Portugal, Madrid.

González, J. - SAquete, J. C. (eds.): Colonias de César y Augusto en la Andalucía romana, Roma.

Gutiérrez Behemerid, M. A. (1990): "Frisos dóricos funerarios en la Península Ibérica: sistematización y cronología”, Boletín del Seminario de Arte y Arqueología de Valladolid 56, 205-217.

Hesberg, $\mathrm{H}$.

(1992): Römische Grabbauten, Darmstadt.

(1993): "Römische Grabbauten in den spanischen Provinzen", [en] W. Trillmich et alii (eds.), Hispania Antiqua. Denkmäler der Römerzeit, Mainz, 159-181.

Hesberg, H. vON - ZANKer, P. (eds.) (1987): Römische Gräberstrassen. Selbstdarstellung Status-Standard, München. 
JiMÉNEZ DíEz, A. (2008): Imagines Hibridae. Una aproximación postcolonialista al estudio de las necrópolis de la Bética (=Anejos de AEspA XLIII), Madrid.

López de la Orden, M. D. (2009): “Ajuar de la tumba de una niña”, [en] J. Alonso (coord.), La mujer en el mundo antiguo en el Museo de Cádiz, Cádiz, 120-121.

Loza Azuaga, M. L. (2010): "Vestido y estatus. Representaciones de luto en la estatuaria romana", Archivo Español de Arqueología 83, 281-301.

Luzón Nogué, J. M. (2010): “Manufacturas”, [en] P. León (coord.), Arte Romano de la Bética. Mosaico. Pintura. Manufacturas, Sevilla, 275-365.

MÁRQuez Moreno, C. et ALII (eds.) (2014): Torreparedones. Investigaciones arqueológicas (2006-2012), Córdoba.

Mora Serrano, B. - Cruz Andreotti, G. (eds.) (2012): La etapa neopúnica en Hispania y el Mediterráneo centro occidental: identidades compartidas, Sevilla.

Moretti, J.-CH. - TARDy, D. (eds.) (2006): L'architecture funéraire monumentale. La Gaule dans l'Empire romain, Paris.

Murillo Redondo, J. F. et ALII (2002): "Los monumentos funerarios de Puerta de Gallegos. Colonia Patricia Corduba", [en] D. Vaquerizo (ed.), Espacio y usos funerarios en el Occidente romano, vol. II, Córdoba, 247-274.

Noguera Celdrán, J. M. - Rodríguez Oliva, P. (2008): "Scultura ispanica in época republicana: note su generi, iconografía, usi e cronologia”, [en] Iberia e Italia: Modelos romanos de integración territorial, Murcia, 379-454.

Pachón Romero, J. A. - Ruiz Cecilia, J. I. (2006): Las Cuevas de Osuna. Estudio históricoarqueológico de una necrópolis rupestre de la Antigüedad, Osuna.

PÉREz LóPEz, I. (1999): Leones romanos en Hispania, Madrid.

Precht, G. (1975): Das Grabmal des Lucius Poblicius: Rekonstruktion und Aufbau, Köln.

Quesada SANZ, F. (2008): “Armamento romano e ibérico en Urso (Osuna): testimonio de una época", Cuadernos de los Amigos de los Museos de Osuna 10, 13-19.

RodríGuez Oliva, P.

(1982): "El conjunto de hermae-retratos de Obulco", Baetica 5, 133-144.

(1991-1992): "Una urna excepcional de la necrópolis romana de Gades", Mainake 13-14, 115-132.

Rodríguez Oliva, P. - Beltrán Fortes, J. (1997-1998): "Nuevas noticias para la localización de la urna cineraria de Gades de la colección de antigüedades de Guillermo de Tyrry, Marqués de la Cañada", Mainake 19-20, 163-169.

Rodríguez TEMIÑo, I. ET ALII (2012): “Acerca de las nuevas investigaciones en la necrópolis romana de Carmona”, Spal 21, 127-151.

Rolland, H. (1969): Le Mausolée de Glanum (Saint-Rémy-de-Provence) (=Gallia Suppl. 21), Paris.

Ruiz Osuna, M. B.

(2008): La monumentalización del mundo funerario en Baetica, Córdoba (tesis doctoral). (2010): Colonia Patricia. Centro difusor de modelos. Topografia y monumentalización funeraria en Baetica, Córdoba.

Ruiz OsunA, M. B. - OrTiz, L. (2009): "La guirnalda funeraria y su relación con los monumentos en forma de edícola: una propuesta de difusión para el sur peninsular", Anales de Arqueología Cordobesa 20, 95-124. 
Santa Maria Scrinari, V. (1972): Museo Archeologico di Aquileia. Catalogo delle Sculture Romane, Roma.

Scholz, M. (2012): Grabbauten in den nördlichen Grenzprovinzen des römischen Reiches zwischen Britannien und dem Schwarzwen Meer, 1- 3 Jahrhundert n. Chr., Mainz.

Torelli, M. (1965): "Monumenti funerari romani con fregio dorico", Dialoghi di Archeologia 2, 32-54.

VAQUERIZO GIL, D.

(2002): "Recintos y acotados funerarios en Colonia Patricia Corduba", Madrider Mitteilungen 43, 168-206.

(2002a): "Espacio y usos funerarios en Corduba", [en] D. Vaquerizo (ed.), Espacio y usos funerarios en el Occidente romano, vol. II, Córdoba, 143-200.

(2006): "Sobre la tradición púnica, o los influjos norteafricanos, en algunas manifestaciones arqueológicas del mundo funerario hispano-bético de época pleno-imperial. Una revisión crítica", [en] D. Vaquerizo - J. Murillo (eds.), El concepto de lo provincial en el mundo antiguo. Homenaje a Pilar León, vol. II, Córdoba, 317-380.

(2008): "Figurative imagery of the deceased in the eastern necropolis of Baelo Claudia (Baetica, Spain)", [en] E. La Rocca - P. León - C. Parisi Presicce (eds.), Le due patrie acquisite. Studi di Archeología dedicati a Walter Trillmich (=Bullettino della Commissione Archeologica Comunale di Roma Suppl. 18), Roma, 419-434.

(2010): Necrópolis urbanas en Baetica, Tarragona.

VAquerizo GiL, D. (ed.) (2010a): Las áreas suburbanas en la Ciudad Histórica. Topografía, usos, función, Córdoba.

VAquerizo, D. - Garriguet, J. A. - León, A. (eds.) (2006): Espacio y usos funerarios en la ciudad histórica (=Anales de Arqueología Cordobesa 17, 1-2), Córdoba. 